\title{
A PROSPECTIVE STUDY OF INCIDENCE OF DEEP VEIN THROMBOSIS AND OUTCOME IN HOSPITALISED PATIENTS WITH BURNS IN A TERTIARY CARE HOSPITAL, WARANGAL URBAN
}

\author{
L. Murali1 ${ }^{1}$ Y. Kavitha ${ }^{2}$
}

${ }^{1}$ Assistant Professor, Department of Community Medicine, Kakatiya Medical College, Warangal, Telangana, India.

${ }^{2}$ Assistant Professor, Department of Plastic Surgery, Kakatiya Medical College, Warangal, Telangana, India.

\begin{tabular}{l}
\hline ABSTRACT \\
BACKGROUND \\
Deep vein thrombosis has increasingly been recognized as an important and possibly preventable cause of morbidity and mortality \\
in hospitalized patients. Deep vein thrombosis is not uncommon in burns patients. We wanted to study the incidence of deep vein \\
thrombosis and the natural course of disease in burns patients.
\end{tabular}

\section{METHODS}

This is an observational study done in MGM Hospital, Warangal, a tertiary care centre, from November 12, 2015 to January 12, 2018, Warangal during study period. The study included patients with an acute burn injury but without accompanying blunt or penetrating trauma, with a total burn area of 15\%-55\%, from both genders, with a radiographically (Doppler/MR Venogram) proven deep vein thrombosis, above 10 years of age, and who were willing to sign informed consent. Exclusion criteria included age below 10 years, severe medically compromised patients, patients on immunosuppressive drugs, total body surface area of burn $<15 \%$ and $>55 \%$, non-thermal burns, patients who did not come for follow up and duration of hospital stay $<4$ days.

\section{RESULTS}

Out of 2548 admissions, 778 were included in the study, 25 were found to be with deep vein thrombosis. Incidence was $3.2 \%$. Highest incidence was in 21-30 years age group, in females, patients with higher TBSA and who presented between 35-45 days of burn injury.

\section{CONCLUSIONS}

Right Lower Limb had highest incidence 56\%, Left Lower Limb 28\%. Most commonly, deep vein thrombosis presented extending from popliteal vein to external iliac vein (68\%). 36\% of cases had an average time of femoral cannulation of five weeks. Most of the patients who developed deep vein thrombosis had continuous immobilization (48\%) for > 2 wks., $56 \%$ after surgery. $52 \%$ of burn patients with inhalation injury.

\section{KEY WORDS}

DVT- Deep Vein Thrombosis, Burns

HOW TO CITE THIS ARTICLE Murali L, Kavitha Y. A prospective study of incidence of deep vein thrombosis and outcome in hospitalised patients with burns in a tertiary care hospital, Warangal urban. J. Evolution Med. Dent. Sci. 2019;8(28):2288-2294, DOI: $10.14260 /$ jemds/2019/501

\section{BACKGROUND}

In the past decade, deep vein thrombosis, has increasingly been recognized as an important and possibly preventable cause of morbidity and mortality in hospitalized patients. Deep vein thrombosis is not uncommon in burns patients. Understanding the natural history of venous thrombosis is important for optimal management of this condition. Thermally injured patients have multiple risk factors for venous thrombosis. Once risk factors are recognized it is possible to avoid these risk factors or to use active prophylaxis to reduce the morbidity and mortality. Deep vein thrombosis is generally related to factors included under the classical triad of stasis, vessel wall damage and hypercoagulability. In particular, the association of hypercoagulability with venous stasis, which allows accumulation of activated coagulation factors in venous

'Financial or Other Competing Interest': None.

Submission 13-05-2019, Peer Review 26-06-2019,

Acceptance 05-07-2019, Published 15-07-2019.

Corresponding Author:

Dr. Y. Kavitha,

Assistant Professor, Department of Plastic Surgery,

H. No. 3-1-307/3, Kakatiya Colony,

Warangal Urban-506011, Telangana, India.

E-mail: kavilingala@gmail.com

DOI: $10.14260 /$ jemds $/ 2019 / 501$ valve sinuses of the calf are presently regarded as the primary triggering mechanism in development of most venous thrombi. The primary (inherited) abnormalities in some of the natural inhibitors of coagulation are associated with an increased risk of venous thrombosis. Approximately $50 \%$ of cases of deep vein thrombosis were considered to be secondary (acquired) to major risk factors like immobilization, trauma, burns and recent surgery. Among additional risk factors, increased age (over 60 years), male gender, increased total body surface area of burn, inhalation injury and blood transfusions were independently associated with the risk of acute deep vein thrombosis. There is a need to study the clinical presentation and risk factors associated with deep vein thrombosis, in patients with burns as there is little published information available from India. This study is aimed at identifying the incidence, natural course, and outcome of deep vein thrombosis amongst patients with burn injuries, in South India at a tertiary care Hospital such as Kakatiya Medical College/MGM Hospital.

\section{METHODS}

It was a prospective study conducted in Department of Plastic surgery MGM Hospital, Warangal by Community Medicine Department in the period between November 2015 and January 2018. 


\section{Source of Data}

Study population consisted of all admissions with thermal burns in MGM Hospital, Warangal between November 2015 and January 2018.

\section{Inclusion Criteria}

Burn patients with total body surface area $15 \%$ to $55 \%$, both genders, Patients with Colour Doppler proven deep vein thrombosis and Age between 10 and 50 years.

\section{Exclusion Criteria}

Age below 10 years and above 50 years, Severe medically compromised patients, Patients on immunosuppressive drugs, Burn patients with total body surface area $<15 \%$ and $>55 \%$, Non Thermal burns, Patients who did not come for follow up, duration of Hospital stay $<4$ days.

\section{Institutional Ethical Clearance}

Clearance from ethical committee of the Kakatiya Medical College, Warangal was obtained before starting the study.

\section{Methodology of Study}

The case history and physical examination was done according to the enclosed Proforma after taking the informed consent. Informed Consent was taken from the patients after explaining the purpose and procedure of the study before interviewing, examining and taking blood samples of the patient. All patients admitted with thermal burns were resuscitated and given other treatment for burns and physiotherapy. All patients were observed for any clinical symptoms and signs for deep vein thrombosis. If any clinical suspicion noted, they were evaluated by colour doppler/Computed tomography. Investigation like prothrombin time, activated partial thromboplastin time, International normalised ratio were done.

\section{Criteria for Assessment of Incidence}

Age Gender, Percentage of burns, Clinical presentation, Pain, Swelling, Redness, Type of intravenous line, Duration of intravenous line, duration of Immobilisation of the patient and limb, duration of hospitalization, Number of surgeries, Type of surgeries, Burn wound complications. Patients who developed clinical signs of deep vein thrombosis were started on anticoagulant therapy, low molecular weight heparin $40 \mathrm{mg}$, subcutaneously, twice daily for five days, warfarin two milligram orally once daily from third day onwards and all patients were advised complete bed rest and their progress monitored regularly with weekly investigations. Clinical observation was done for the progress or resolution of deep vein thrombosis, burn wound complications, any clinical features of pulmonary embolism, and they were followed with colour doppler until patient's health status improvement for an average six to eight weeks. Surgeries were contemplated after recanalisation started; it was an average of six weeks from the time of diagnosis of deep vein thrombosis. Patients were advised to stop warfarin at least five days before surgery. Patients were advised to continue anti-coagulant treatment, stockings after the surgery and were observed for any features of complication of deep vein thrombosis and burn wound related complications.

\section{RESULTS}

2548 patients were admitted with thermal burns during the study period. 778 patients were included in inclusion criteria and 25 cases were found to be with deep vein thrombosis.

\section{Age Distribution}

Patients were grouped as up to 10 years, 11-20 yrs., 21-30 yrs., 31-40 yrs., 41-50 yrs. at interval of $10 \mathrm{yrs}$. Most of the patients were between $21-30$ yrs. of age (40\%). Then $32 \%$ of patients were in 31-40 yrs. The mean age of the study group was 35.8 years ranging from 13 to $50 \mathrm{yrs}$.

\section{Gender Distribution}

Out of the 25 patients, $36 \%$ of those affected with deep vein thrombosis were males and $64 \%$ were females. The mean age of males and females was 35.45 year and 36.47 years respectively.

\section{Total Body Surface Area of Burn}

Patients were grouped as $15-25 \%, 26-35 \%, 36-45 \%, 46-55 \%$ at interval of ten percentage. Incidence of deep vein thrombosis increased with increase in total body surface area of burn. Highest incidents of deep vein thrombosis were found in 46$55 \%$ (48\%). Next highest incident was found in $35-45 \%$ (24\%).

\section{Sites of Thrombosis}

Venous thrombosis of the limbs was diagnosed by Doppler study. 14 patients (56\%) had right lower limb venous thrombosis and 7 patients (28\%) had left lower limb venous thrombosis. None of them had upper limb venous thrombosis. Unilateral right lower limb had highest incidence of presentation which was $56 \%$. Followed by unilateral left lower limb which was $28 \%$. No upper limb cases were noted on symptomatic evaluation.

\section{Incidence of Extent of Involvement of Thrombosis}

Venous thrombosis of the limbs was diagnosed by doppler study. 17 patients $(68 \%)$ had deep vein thrombosis extending from popliteal vein to External iliac vein, four patients (16\%) had extending from Great saphenous vein to external iliac vein. Eight percent of patients had femoral vein thrombosis.

\section{Intravenous Line}

An access to the Great saphenous vein was established with a venesection in all patients on admission. In all the cases it was converted to a central line by securing an access to the femoral vein by a long length cannula on day three or day four by when the venesection got invariably blocked or showed leak. One patient had developed deep vein thrombosis after venesection. Rest all had femoral vein cannula and $24 \%$ of patients developed within 15 days of cannulation, $20 \%$ developed after $16^{\text {th }}$ day and within 25 days of cannulation. $26 \%$ of patients had cannula retained for a period of 35 days to 55 days.

\section{Causes of Immobilisation}

All patients were advised early mobilization and physiotherapy, but few patients did not follow early mobilization, either due to post-operative surgery/plaster casting/noncompliance of patient/ attenders, intra venous line, burns in lower limbs. Amongst those developing deep vein thrombosis $48 \%$ were found to be immobilized for two weeks. Eight percent of patients were found not to have mobilized for up to 45 days. 


\section{Clinical Presentation}

Twenty-five patients presented with lower limb deep vein thrombosis. The most common presenting features were swelling of the limb in 13 patients $(52 \%)$ and pain in nine patients $(36 \%)$. Two patients $(8 \%)$ also had associated symptoms of breathlessness, chest pain and orthopnea. Pulmonary embolism was ruled out by computed tomography chest and other patient died probably due to sepsis.

\section{Analysis of Presenting Features}

Lower Limb deep vein thrombosis in 25 patients, and splenic vein, portal vein and hepatic vein thrombosis seen in 1 patient. On general examination, 24 patients $(96 \%)$ had pedal oedema and calf tenderness was found in 21 patients (84\%). One patient was found to have portal vein and hepatic vein thrombosis and one patient presented with abdominal pain and jaundice.

\begin{tabular}{|l|l|l|}
\hline Involved Limb & Number of Cases & Incidence \\
\hline Right lower limb & 14 & $56 \%$ \\
\hline Left lower limb & 7 & $28 \%$ \\
\hline Both lower limb & 4 & $16 \%$ \\
\hline Upper limb Table 1. Incidence of Site of Thrombosis \\
\hline \multicolumn{2}{|c|}{} \\
\hline
\end{tabular}

\begin{tabular}{|l|l|l|}
\hline No. of Days of Continuous Immobilization & No. of Patients & Percentage \\
\hline 1-7 days ( one week) & 11 & $44 \%$ \\
\hline 8-14 days (Two weeks) & 12 & $48 \%$ \\
\hline 15-21 days ( Three weeks) & 1 & $4 \%$ \\
\hline 22-28 days (Four weeks) & 1 & $4 \%$ \\
\hline \multicolumn{2}{|c|}{} \\
\hline
\end{tabular}

\begin{tabular}{|l|l|l|}
\hline Symptoms and Signs & No. of Patients (N=25) & $(\mathbf{\%})$ \\
\hline Swelling & 18 & $72 \%$ \\
\hline Pain & 9 & $36 \%$ \\
\hline Short ness of breath/Chest pain/Orthopnea & 2 & $8 \%$ \\
\hline Oedema & 24 & $96 \%$ \\
\hline Redness & 6 & $24 \%$ \\
\hline Calf tenderness & 22 & $88 \%$ \\
\hline Homan's sign & 8 & $32 \%$ \\
\hline Table 3. Analysis of Symptoms and Signs of Limb Deep Vein Thrombosis \\
\hline
\end{tabular}

\begin{tabular}{|l|l|l|l|l|l|l|}
\hline & Hb & TC & PC & ESR & INR & APTT \\
\hline N(number of patients) & 25 & 25 & 25 & 25 & 25 & 25 \\
\hline Mean & 11.512 & 8,324 & 2.29 & 22.28 & 1.226 & 33.12 \\
\hline Median & 11.5 & 7,550 & 2.1000 & 19.5 & 1.1 & 31 \\
\hline Std. Deviation & 1.3409 & 3514.826 & 0.7822 & 11.2830 & 0.36298 & 8.4747 \\
\hline Range & 6 & 17,800 & 3.1 & 42 & 1.8 & 45 \\
\hline Minimum & 8.1 & 3,200 & 1 & 10 & 1 & 25 \\
\hline Maximum & 14.1 & 21,000 & 4.1 & 62 & 2.8 & 70 \\
\hline \multicolumn{7}{|c|}{ Table 4. Investigation Profiles } \\
\hline
\end{tabular}

\begin{tabular}{|l|l|l|}
\hline $\begin{array}{l}\text { Period for Partial Recanalization } \\
\text { from the Time of Noticing the DVT }\end{array}$ & No. of Patients & $\begin{array}{l}\text { Percentag } \\
\text { e }\end{array}$ \\
\hline$<1$ month & 1 & $4 \%$ \\
\hline 1-2 months & 1 & $4 \%$ \\
\hline $2-3$ months & 1 & $4 \%$ \\
\hline $3-4$ months & 8 & $32 \%$ \\
\hline $4-5$ months & 3 & $12 \%$ \\
\hline $5-6$ months & 4 & $16 \%$ \\
\hline $6-7$ months & 1 & $4 \%$ \\
\hline $7-8$ months & 1 & $4 \%$ \\
\hline$>8$ months & 1 & $4 \%$ \\
\hline \multicolumn{2}{|l|}{ Table 5. Time Taken for Recanalization of Deep Vein Thrombosis } \\
\hline
\end{tabular}

\begin{tabular}{|l|l|l|l|l|}
\hline $\begin{array}{l}\text { Sign and } \\
\text { Symptoms }\end{array}$ & $\begin{array}{l}\text { O Donnell } \\
\text { et al }^{\mathbf{1}}\end{array}$ & $\begin{array}{l}\text { Haeger } \\
\text { et al }^{\mathbf{2}}\end{array}$ & $\begin{array}{l}\text { Molly } \\
\text { et al }^{\mathbf{3}}\end{array}$ & $\begin{array}{l}\text { Present } \\
\text { Study }\end{array}$ \\
\hline & $\% \mathrm{DVT}+$ & $\% \mathrm{DVT}+$ & $\% \mathrm{DVT}+$ & $\% \mathrm{DVT}+$ \\
\hline Pain & 78 & 90 & 48 & 36 \\
\hline Tenderness & 76 & 84 & 43 & 84 \\
\hline Oedema & 78 & 42 & 43 & 96 \\
\hline Homan's sign & 56 & 33 & 11 & 56 \\
\hline Swelling & 85 & - & 41 & 52 \\
\hline Erythema & 24 & - & - & 32 \\
\hline \multicolumn{4}{|r|}{ Table 6. Frequency of Symptoms and Signs in Patients } \\
with Suspected Deep Vein Thrombosis \\
\hline Deep vein thrombosis+ indicates those with deep vein thrombosis. \\
\hline
\end{tabular}
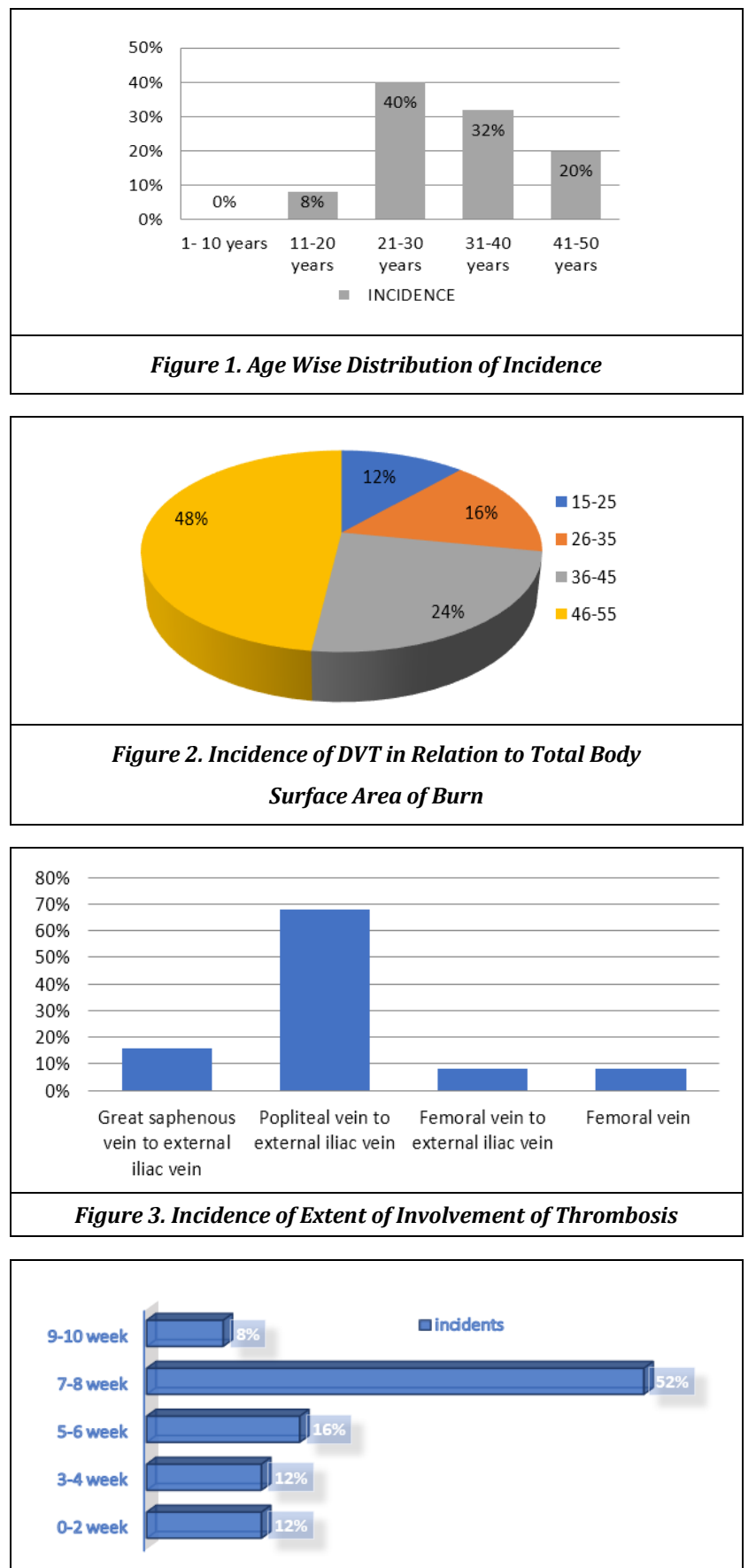

Figure 4. Incidence of Presentation of DVT in Weeks after Burn Injury

Highest incidence of deep vein thrombosis was observed between seventh to eighth week after burn injury which was $52 \%$.

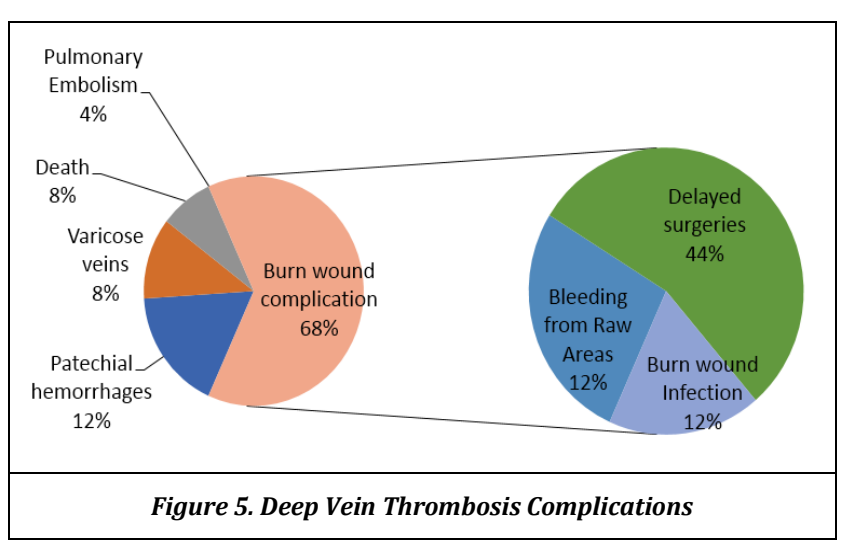




\section{Patients with Pulmonary Embolism}

Out of twenty-five patients, two patients complained chest pain, shortness of breath, cough. Computed tomography of chest was advised to rule out pulmonary embolism, other died due to sepsis. Another patient who complained of abdominal pain was advised computed tomography of abdomen to rule out abdominal vein thrombosis.

\section{Week of Presentation of Deep Vein Thrombosis after Admission}

$52 \%$ of patients presented with deep vein thrombosis in the seventh or eighth week of admission. $16 \%$ of patients presented with deep vein thrombosis in the fifth or sixth week.

\section{Investigation Profile}

Five patients were anaemic with haemoglobin $<10 \mathrm{mg} / \mathrm{dl}$. The mean haemoglobin was $11.51 \mathrm{mg} / \mathrm{dl}$. The white blood cell count ranged between 3200 to 21000 per cu mm, with a mean of 8,324 per cu mm. Five patients had leucocytosis with WBC above $14000 / \mathrm{mm}^{3}$. The mean platelet count was 2.29 lakh per cu mm ranging from 0.90 to 4.1 lakh per cu mm. The mean erythrocyte sedimentation rate (ESR) was $22.28 \mathrm{~mm}$ in the first hour ranging from $10 \mathrm{~mm}$ to $62 \mathrm{~mm}$, and one patient had ESR above $55 \mathrm{~mm}$. Prothrombin time (PT)and INR was normal in 45 patients whereas five patients had INR ranging from 1.5 to three. Mean activated partial thrombo plastin time was with a range of 25 to 70 secs. APTT was prolonged (More than 35) in 10 patients. Four patients had deranged liver function tests and 4 patients had elevated renal function tests.

\section{Acquired Risk Factors}

All patients had at least one risk factor which was a predisposition to venous thrombosis. Ten patients (40\%) had two risk factors, 11 patients (44\%) had three risk factors, two patients $(8 \%)$ had 4 risk factors which predisposed to venous thrombosis. Risk factors are Past H/o Thrombosis, Bed rest for more than 3 days, Surgery within 12 weeks, Inhalation injury, Femoral Cannulation/central venous line, Venesection-

1. Past History of Venous Thrombosis- Two patients had history of previous episodes of venous thrombosis due to thermal burns.

2. Immobilization- All patients were motivated for early mobilization, 10 patients had history of bed rest for more than three days.

3. Surgery- 20 patients had history of surgery within 12 weeks, of which 14 patients (56\%) developed lower limb venous thrombosis.

Total recanalisation ----> 8 months - 3 patients (12\%). All patients were monitored with colour doppler every 15 days, because of its availability, non-invasive nature, could be done on outpatient basis. Partial recanalization started between 34 months.

\section{Period of Stay of Patient In The Hospital}

$32 \%$ (Eight) patients stayed in hospital for two months. 48\% patients (12) stayed for four months. Four percent of patients stayed for six to eight months and four percentage of patients stayed for more than eight months.

On follow up of all patients, three patients had Petechial haemorrhagic rash $12 \%$, two patients had developed varicose veins (Eight percent), two patients had associated rash and were managed conservatively. Two deaths were reported eight percent. One patient died probably due to pulmonary embolism. Another died probably due to sepsis.

\section{DISCUSSION}

Deep vein thrombosis is not uncommon in burns patients. Understanding the natural history of venous thrombosis is important for optimal management of this condition. Deep vein thrombosis is generally related to factors included under the classical triad of stasis, vessel wall damage and hypercoagulability. This study was aimed at identifying the incidence, natural course, and outcome in deep vein thrombosis. This study was conducted between November 2015 and January 2018. All patients admitted with thermal burns were observed. In this study 778 patients were included in inclusion criteria of which 25 patients were presented with deep vein thrombosis.

\section{Gender and Age Incidence of Deep Vein Thrombosis}

In this study highest incidence was observed in females (64\%). Female to male ratio was 2: 1.12. Female to male ratio 3.5: 2.4 was also seen in study of Santhosh Rudrappa, Anupama. ${ }^{4}$

The age of patients with deep vein thrombosis ranged from 14 to 50 years. The mean age of the study was 28.2 , highest incidence of deep vein thrombosis was observed in 21-40 years $(72 \%)$.This might be because young people in this group were admitted with higher percentage of thermal burns. in the study of W, L. Wahl, mean age $49 \pm 23$. Age range was between 16-76 years. ${ }^{5}$

\section{Total Body Surface Area of Burn}

In this study, most common presentation of deep vein thrombosis was observed in between $45-55 \%$ of total body surface area of burn (48\%). This is might be due to increased incidence of deep vein thrombosis with increased percentage of burn. ${ }^{6}$ W. L. Wahl study shows $15 \pm 4 \%$ total body surface area of burn. ${ }^{6}$

\section{Clinical Presentation}

All patients in this study had lower limb deep vein thrombosis, the most common presenting features were swelling of the limb in 13 patients (52\%) and pain in nine patients (36\%), two patients (8\%) also had associated symptoms of breathlessness, chest pain and orthopnea. One patient died due to shortness of breath. Computed tomography of chest angiogram did not show Pulmonary Embolism. Another patient died due to sepsis. On general examination, 24 patients (96\%) had pedal oedema and calf tenderness was found in 21 patients $(84 \%)$. The incidence of pulmonary embolism ${ }^{7}$ was low in this study (4\%). This was similar to study by Gavin M. Joyat. ${ }^{8}$ The incidence of pulmonary embolism was low in femoral cannula related deep vein thrombosis. Similar incidence (zero to $0.5 \%$ ) was also noted in W. L. Wahl study.

\section{Sites of Thrombosis}

The most common site of deep vein thrombosis was observed in right lower limb in 14 patients (56\%) followed by left lower limb in seven patients (28\%), $16 \%$ of patients were presented with bilateral involvement. Ratio of incidence of right lower limb to left lower limb was 1.2:1. None of the case presented with upper limb deep vein thrombosis on symptomatic evaluation. Chingalensana study demonstrated that incidence of deep vein thrombosis was less in left lower limb. Ratio of right lower limb to left lower limb 1:1.2. 


\section{Incidence of Extent of Involvement of Thrombosis}

Limb venous thrombosis was diagnosed in all patients by doppler study. The current study demonstrated that, extent of involvement deep vein thrombosis in 17 patients (68\%) was from popliteal vein to external iliac vein, four patients $(16 \%)$ had great saphenous vein to external iliac vein. Two patients (8\%) presented with extent of involvement of deep vein thrombosis from popliteal vein to external iliac vein bilaterally. Isolated femoral vein thrombosis was observed in eight percent of patients. According to western studies, multi segmental involvement of the proximal veins is most common, proximal veins like superficial femoral and popliteal veins being involved in $74 \%$ and $73 \%$ of patients respectively. ${ }^{9}$ However, isolated involvement of the iliac veins may occur in 2 to $5 \%$ of cases, and 12 to $35 \%$ remain confined to the distal limb (calf) veins. ${ }^{10}$

\section{Acquired Risk Factors}

Following acquired risk factors were evaluated in all 25 patients-

1. Past History of Venous Thrombosis- Two patients (8\%) had history of previous episode of venous thrombosis. In the population study by Anderson and colleagues, one third of episodes of acute VTE were recurrent. An increased risk of symptomatic recurrent thromboembolism has been reported among patients failing to achieve a therapeutic activated partial thromboplastin time (APTT) within 24 hours (23.3 versus 4 to 6 ).

2. Immobilization and Surgery- All patients had history of bed rest for more than 3 days in the past, $48 \%$ of patients were found to be immobilized for one week, might be due to post-operative surgery/plaster casting/noncompliance of patient/ attenders, intra venous line in lower limb, burns in lower limbs. Eight percent of patients were found not to have mobilized for up to 45 days and this might be due to raw areas in lower limbs

3. Deep Vein Thrombosis Caused by Femoral Vein Cannulae In Burns- Central venous cannulation via the femoral route has several potential advantages. There is no risk of pneumothorax, the site is directly compressible should bleeding occur, and nerve damage is unlikely. Femoral venous catheters can be inserted with relative ease and have been used successfully in acute resuscitation and severely burned patients. ${ }^{15,16}$

Recent studies in paediatric and adult critically ill patients have concluded that the femoral vein is a useful site for central venous cannulation, ${ }^{17}$ and these studies quoted few complications. Earlier reports of catheter-induced deep venous thrombosis and other complications have resulted in the restricted use of the femoral route for central venous catheterization. ${ }^{18}$ However, because of changes in catheter materials (Modern polyurethane catheters are less thrombogenic than polyvinyl and polyethylene catheters) and improved sterile techniques in recent years, interest in femoral catheterization has increased ${ }^{19}$. As a result, the utility of femoral venous catheters ${ }^{20}$ and the associated complications in critically ill patients are being re-evaluated. Gavin M. Joyat study showed that catheter related deep vein thrombosis in burns was absent/ low. The current study demonstrated that catheter related deep vein thrombosis was high (68\%) and incidence of deep vein thrombosis was more with increased duration of retained catheter. This might be due to gradual endothelial injury while giving medication through intravenous line in zone of injury of burns in lower limbs when there was absence of zone of injury in upper limbs and neck. $36 \%$ of patients had retained femoral cannula for five weeks. Line related deep vein thrombosis can occur any time from the day of insertion to one week after removal. Durbec 0 study suggested that there may be a safe duration of catheterization. ${ }^{21,22}$

The data of the above study clearly show that catheter related deep vein thrombosis may occur at any time, from day one to one week after removal of the catheter and no "safe" period for catheterization exists.

\section{Inhalation Injury}

The current study demonstrated $52 \%$ patients with inhalation injury developed deep vein thrombosis. Ratio of patients with inhalation injury: non inhalation injury $=3: 1$. Christopher study demonstrated this ratio was $2: 1 .^{23}$

\section{Investigation Profile}

The initial laboratory evaluation for patients with venous thrombosis revealed the following four patients had leucocytosis, four patients had raised international normalized ratio. Activated partial thromboplastin time was prolonged (More than 35) in ten patients. Four patients had deranged liver function and four patients had raised renal function tests with renal failure.

Investigations to know the hypercoagulable state of the patients like -protein $\mathrm{C}$ or $\mathrm{S}$ deficiency, antithrombin deficiency, or lupus anticoagulant was not done due to nonaffordability of patients in this study.

Limb venous thrombosis was diagnosed in all patients by doppler study. It was non-invasive, low cost when compared to other investigations, could be done at multiple times and easy for follow up cases. An average number of doppler study for each patient was 3.8. An average duration for radiological confirmation was 6.8 days. The first doppler study gave accurate diagnosis in all cases.

Ultrasound examination was performed with the patient in the supine position when suspected to have deep vein thrombosis clinically and it was done every two weeks until discharge. A follow up ultrasound examination was performed at $24 \mathrm{~h}$ and 1 week after catheter removal.

The deep venous systems of both lower extremities were examined, from the external iliac veins proximally to the popliteal veins distally. The veins were evaluated in the transverse and longitudinal planes using the compression technique of Cronan et al,24 supplemented with duplex and colour doppler capability. Deep vein thrombosis was diagnosed when there was visualization of thrombus, noncompressibility of the vein, no spontaneous doppler flow, lack of phasicity and augmentation, and doppler and colour spectral flow void. The site of deep vein thrombosis was recorded. Scans were performed with a diagnostic ultrasound system, using a high resolution $5-\mathrm{MHz}$ curved linear array probe. All examinations were recorded and reviewed by a radiologist who was unaware of the patient's state of coagulation. 


\section{Consequences of Deep Vein Thrombosis}

In the current study four percentage of patients showed partial recanalization in less than one month, $32 \%$ of patients showed partial recanalization between three to four months. Total recanalization was completed in $12 \%$ of patients in six to nine months. Bergvall study observed recanalization was a late reaction, occurring over periods varying from six months to years. ${ }^{25}$ Killewich et al ${ }^{26}$ observation, demonstrating some evidence of recanalization in $44 \%$ of patients by seven days and $100 \%$ of patients by 90 days.

\section{Effect of Deep Vein Thrombosis on Surgery}

Deep burns need escharectomy by the second week or the beginning of third week. $28 \%$ of patients underwent escharectomy between third and fourth weeks. $40 \%$ of patients had with raw areas for three to four months. $56 \%$ of patients (14) developed deep vein thrombosis after surgery either escharectomy or skin grafting. Those who developed deep vein thrombosis were treated with anticoagulant therapy starting with low molecular weight heparin $40 \mathrm{mg}$ subcutaneously for first five days, then warfarin $2 \mathrm{mg}$ orally from third day on wards. These patients were subjected to surgery after partial recanalisation had started which was noticed six to eight weeks of anticoagulant therapy. $60 \%$ of patients in this study underwent surgery between three to four months after admission, most of the patients underwent surgery for more than two times. The presence of deep vein thrombosis had delayed surgeries by an average of about nine to twelve weeks and these patients had to wait for resurfacement of their raw areas by about nine to twelve weeks.

\section{CONCLUSIONS}

Out of 2548 admissions, 778 were included in the study, 25 were found to be with deep vein thrombosis. Incidence was $3.2 \%$. Highest Incidence was seen in 21-30 years age group, females, higher TBSA, presented between 35-45 days of burn injury. Right Lower Limb had highest incidence 56\%, Left Lower Limb 28\%. Most commonly deep vein thrombosis extended from popliteal vein to external iliac vein (68\%). 36\% of cases had an average time of femoral cannulation for five weeks. Most of the patients who developed deep vein thrombosis had continuous immobilization (48\%) for $>2 \mathrm{wks.}$ $56 \%$ after surgery. $52 \%$ were burn patients with inhalation injury.

\section{Recommendations}

Early mobilization should be advised after surgeries. All patients should be advised stockings for deep vein thrombosis.

\section{REFERENCES}

[1] O'Donnell TF, Abbott WM, Athanasoulis CA, et al. Diagnosis of deep venous thrombosis in the outpatient by venography. Surg Gynecol Obstet 1980;150(1):69-74.

[2] Haeger K. Problems of acute deep venous thrombosis. I. The interpretation of signs and symptoms. Angiology 1969;20(4):219-23.

[3] Merli GJ. Pathophysiology of venous thrombosis, thrombophilia and the diagnosis of deep vein thrombosis - pulmonary embolism elderly. Clinics in Geriatric Medicine 2006;22(1):75-92, viii-ix.
[4] Chinglensana L, Rudrappa S, Anupama K, et al. Clinical profile and management of deep vein thrombosis of lower limb. Journal of Medical Society 2013;27(1):1014.

[5] Wahl WL, Brandt MM, Ahrns KS, et al. Venous thrombosis incidence in burn patients: preliminary results of a prospective study. J Burn Care Rehabil 2002;23(2):97-102.

[6] Caprini JA. Thrombosis risk assessment as a guide to quality patient care. Dis Mon 2005;51(2-3):70-8.

[7] Baglin C, Brown K, Luddington R, et al. Risk of recurrent venous thromboembolism in patients with the factor $\mathrm{V}$ Leiden (FVR506Q) mutation: effect of warfarin and prediction by precipitating factors. East Anglian Thrombophilia Study Group. Br J Haematol 1998;100(4):764-8.

[8] Joynt GM, Kew J, Gomersall CD, et al. Deep venous thrombosis caused by femoral venous catheters in critically ill adult patients. Chest 2000;117(1):178-83.

[9] Huisman MV, Buller HR, ten Cate JW, et al. Unexpected high prevalence of silent pulmonary embolism in patients with deep venous thrombosis. Chest 1989;95(3):498-502.

[10] Rosfors S, Eriksson M, Leijd B, et al. A prospective followup study of acute deep venous thrombosis using colour duplex ultrasound, phlebography and venous occlusion plethysmography. Int Angiol 1997;16(1):39-44.

[11] Hagley MT, Martin B, Gast P, et al. Infectious and mechanical complications of central venous catheters placed by percutaneous venipuncture and over guidewires. Crit Care Med 1992;20(10):1426-30.

[12] Seneff MG. Central venous catheters. In: Rippe JM, Irwin RS, Fink MP, et al, eds. Intensive care medicine. Boston, MA: Little Brown 1996: p. 15-35.

[13] Mangiante EC, Hoots AV, Fabian TC. The percutaneous common femoral vein catheter in critically injured patients. J Trauma 1988;28(12):1644-9.

[14] Anderson FA Jr, Wheeler HB, Goldberg RJ, et al. a population based perspective of the hospital incidence and case-fatality rate of deep vein thrombosis and pulmonary embolism. Arch Intern Med 1991;151(5):933-8.

[15] Swanson RS, Uhlig PN, Gross PL, et al. Emergency intravenous access through the femoral vein. Ann Emerg Med 1984;13(4):244-7.

[16] Purdue GF, Hunt JL. Vascular access through the femoral vessels: indications and complications. J Burn Care Rehabil 1986;7(6):498-500.

[17] Williams JF, Seneff MG, Friedman BC, et al. Use of femoral venous catheters in critically ill adults: prospective study. Crit Care Med 1991;19(4):550-3.

[18] Moncrief JA. Femoral catheters. Ann Surg 1958;147(2):166-72.

[19] Smyrnios NA, Irwin RS. The jury on femoral vein catheterization is still out. Crit Care Med 1997;25(12):1943-6.

[20] Agee KR, Balk RA. Central venous catheterization in the critically ill patient. Crit Care Clin 1992;8(4):677-86.

[21] Durbec O, Viviand X, Potie F, et al. A prospective evaluation of the use of femoral venous catheters in critically ill adults. Crit Care Med 1997;25(12):1986-9. 
[22] Trottier SJ, Veremakis C, O’Brien J, et al. Femoral deep vein thrombosis associated with central venous

[23] Pannucci CJ, Osborne NH, Park HS, et al. Acquired inpatient risk factors for venous thromboembolism after thermal injury. J Burn Care Res 2012;33(1):84-8.

[24] White RH, McGahan JP, Daschbach MM, et al. Diagnosis of deep-vein thrombosis using duplex ultrasound. Ann Intern Med 1989;111(4):297-304. catheterization: results from a prospective randomized trial. Crit Care Med 1995;23(1):52-9.

[25] Bergvall U, Hjelmstedt A. Recanalisation of deep venous thrombosis of the lower leg and thigh. A phlebographic study of fracture cases. Acta Chir Scand 1968;134(3):219-28.

[26] Killewich LA, Bedford GR, Beach KW, et al. Spontaneous lyses of deep venous thrombi: rate and outcome. J Vasc Surg 1989;9(1):89-97. 